\title{
CLASSIFICATION OF LOOPS OF LAMPBRUSH CHROMOSOMES ACCORDING TO THE ARRANGEMENT OF TRANSCRIPTIONAL COMPLEXES
}

\author{
U. SCHEER, W. W. FRANKE, M. F. TRENDELENBURG \\ AND H. SPRING \\ Division of Membrane Biology and Biochemistry, Institute of Experimental \\ Pathology, German Cancer Research Center, D-69 Heidelberg, Federal \\ Republic of Germany
}

\section{SUMMARY}

The arrangement of transcriptional units in the loops of lampbrush chromosomes from oocyte nuclei of urodele amphibia and from primary nuclei of the green alga Acetabularia have been studied in the electron microscope using spread preparations. Loops with different patterns of arrangement of matrix units (i.e. to a first approximation, transcriptional units) can be distinguished: (i) loops consisting of one active transcriptional unit; (ii) loops containing one active transcriptional unit plus additional fibril-free, i.e. apparently untranscribed, intercepts that may include 'spacer' regions; (iii) loops containing two or more transcriptional units arranged in identical or changing polarities, with or without interspersed apparent spacer regions. Morphological details of the transcriptional complexes are described. The observations are not compatible with the concept that one loop reflects one and only one transcriptional unit but, rather, lead to a classification of loop types according to the arrangement of their transcriptional units. We propose that the lampbrush chromosome loop can represent a unit for the coordinate transcription of either one gene or a set of several (different) genes.

\section{INTRODUCTION}

Lampbrush chromosomes offer the unique possibility of studying structural aspects of transcription within individual, cytologically defined subunits of chromosomes, the 'chromomeres' (for definition see the recent review by Lima-de-Faria, I975). In certain stages of the meiotic prophase during spermatogenesis and oogenesis in various animals, parts of the chromomeric DNP unravel and extend into the characteristic lateral loops that are terminally inserted in the condensed portion of the chromomere (for reviews see Gall, I954; Wischnitzer, I957; Callan \& Lloyd, I96o $a$; MacGregor \& Callan, I962; Callan, I963; Kunz, r967; Hess, I97 r Mott \& Callan, I975). Similar lampbrush-type chromosomes with defined axes, chromomeres and lateral loops have recently been described in the primary nuclei of the green alga Acetabularia (Spring et al. I975). Usually the lateral loops of lampbrush chromosomes have lengths of $10-50 \mu \mathrm{m}$ but some individual loops, especially in amphibian oocytes, can be as long as $200 \mu \mathrm{m}$. From autoradiographic studies it is known that the chromatin axes contained in these loops are involved in transcription and that their RNA synthesis is sensitive to actinomycin D (Izawa, Allfrey \& Mirsky, I963; 
Snow \& Callan, I969). In amphibian oocytes, the RNA synthesized on the lateral loops seems to be very large and heterogeneous in size (from Io to Ioo s) and reflects the base composition of total chromosomal DNA (Sommerville, 1973; Sommerville \& Malcolm, 1976). Messenger RNA-like sequences are present in these RNA molecules, as demonstrated by hybridization with complementary DNA derived from oocyte poly-A containing mRNA (Sommerville \& Malcolm, I976). The majority of the loops are uniformly labelled over their whole length shortly after addition of an RNA precursor, whereas a few specific loops are labelled vectorially and sequentially (Gall \& Callan i962; Snow \& Callan, I969). These studies suggest that a substantial portion, if not all, of the DNA within a loop is being transcribed into long precursor molecules containing mRNA sequences. This conclusion is in agreement with light-microscopical observations that the matrix material, which contains non-basic proteins (Sommerville, 1973; Hill, Maundrell \& Callan, 1974; Maundrell, 1975) and RNA (Gall, I954; MacGregor \& Callan, I962; Miller, I965; Sommerville, I973), covers the entire loop axis and often shows a polarity in its thickness starting from one chromomeric insertion point. It is also in accord with electron-microscope observations of lampbrush chromosomes (sectioned or whole-mount spread) prepared to preserve the matrix material in a relatively compact state, e.g. at moderately high salt concentrations or at low pH (Tomlin \& Callan, I95 I ; Guyénot \& Danon, I953; Miller, I965; Gall, I966; Ris, I969; Ullerich, I970; Malcolm \& Sommerville, I974; Meyer \& Hennig, I974 $a$; Mott \& Callan, I975). When lampbrush chromosomes are exposed to very low salt conditions, especially at slightly alkaline $\mathrm{pH}$, the matrix material disperses rapidly and is no longer visible in the light microscope (Tomlin \& Callan, I95 I ; Gall, I954, 1956; Wischnitzer, 1957; Callan, 1963). Electron-microscopical studies of spread preparations of such swollen chromosomes have shown that numerous transcriptional complexes are attached to each loop axis and that the lateral ribonucleoprotein (RNP) fibrils which contain the nascent RNA are often arranged in an uninterrupted length gradient between both ends of a loop (Miller, I 965 ; Miller, Beatty \& Hamkalo, I972; Meyer \& Hennig, I974a). Consequently, all models of lampbrush chromosome loops are based on the assumption that initiation and termination sites for RNA transcription are located close to the morphological insertion sites at the axial chromomere knob, and that the transcriptional unit extends over the entire loop length (Malcolm \& Sommerville, 1974; Paul, 1975; Sommerville \& Malcolm, I976). The resulting primary transcript is thought to consist of a single copy of mRNA sequence ('informative part') attached to an RNA intercept containing intermediately repetitive sequences ('non-informative' or 'regulatory' part; for detailed discussion see Rosbash, Ford \& Bishop, 1974; Sommerville \& Malcolm, I976; c.f. also Georgiev, I974).

Several recent biochemical and morphological findings, however, are not compatible with the 'one loop - one transcriptional unit' concept. The loops which transcribe $5 \mathrm{~S}$ ribosomal RNA have been identified in oocytes of newt species by in situ hybridization (Barsacchi-Pilone et al. 1974; Pukkila, 1975). Since the $5 \mathrm{~s}$ genes are highly reiterated and clustered, these specific loops probably contain multiple, tandemly arranged transcriptional units. In addition, spread preparations of primary nuclei of 
Acetabularia (Spring et al. I974, I975), spermatocytes of Drosophila (Hennig, Meyer, Hennig \& Leoncini, I974), and oocytes of Pleurodeles (Angelier \& Lacroix, I975) have indicated that more than one transcriptional unit may be present within a single loop.

The relationship between chromomere-loop structures and transcriptional units is of basic interest for the understanding of chromosomal organization in eukaryotes (cf. Beerman, I972; Lima-de-Faria, I975). We have therefore carried out a detailed electron-microscopic study on spread lampbrush chromosomes from various amphibian oocytes and from primary nuclei of various dasycladacean green algae. Our observations of differences in the numbers and modes of arrangement of transcriptional units in different loops have led us to classify the individual loops according to the morphology of the transcriptional units.

\section{MATERIALS AND METHODS}

\section{Terminology}

Intercept, the region of a chromatin strand between any two given reference points in a transscriptional event. Transcriptional complex, the chromatin-associated particle containing the RNA polymerase and the attached nascent ribonucleoprotein (RNP) fibril. Transcriptional unit, the intercept that is transcribed by a RNA polymerase into one covalent ribopolynucleotide, i.e. an intercept limited by a promoter and a terminator site. Matrix unit, the intercept covered with a series of lateral fibrils which increase in length from one point (the starting point) or, at least, all of which are longer than the fibril at the starting point (the latter to allow for potential processing events or higher packing density of the nascent RNA which may lead to subsequent fibril shortening). With relatively long intercepts, the matrix unit defines the minimal size of the corresponding transcriptional unit. In the context of the present article, matrix unit is used as an operational term synonymous with transcriptional unit. Spacer unit, the morphologically identified intercepts (corresponding to the 'apparent spacer units' in nucleolar chromatin; cf. Franke et al. 1976) not covered with lateral fibrils, i.e. which lie between matrix units. $H n-R N A$, heterogeneous nuclear RNA, a class of high-molecular-weight RNA which contains precursor molecules to mRNA (pre-mRNA; cf. Georgiev, 1974).

\section{Source of material and procedures}

The lampbrush chromosomes studied were obtained from early vitellogenic oocytes of the amphibian species Triturus cristatus, T. alpestris, Pleurodeles waltli, and from the primary nuclei of the green algae Acetabularia mediterranea, A. major and A. cliftonii shortly before cap formation (for cultivation conditions see Spring et al. 1974).

The giant nuclei from both the animal and plant cells were manually isolated in ' 5 : I solution' (5 parts $0.1 \mathrm{M} \mathrm{KCl}$ and I part $0.1 \mathrm{M} \mathrm{NaCl}$; i.e. $83 \mathrm{~mm} \mathrm{KCl}$ and I $7 \mathrm{mM} \mathrm{NaCl}$; Callan \& Lloyd, I $960 b$ ) buffered to $\mathrm{pH} 7 \cdot 2$ with Io mM Tris- $\mathrm{HCl}$ and washed free of cytoplasm by repeated excursions through a pipette. For light-microscopical preparations the nuclear envelope was removed using fine needles and the lampbrush chromosomes were spread according to the procedure ('permanent mounts') described in detail by Gall (I966). For electron microscopy the isolated nuclei were transferred into a drop of $0.1 \mathrm{~mm}$ borate buffer $\left(\mathrm{pH} 8 \cdot 5-9 \cdot 0 ; \mathrm{I}^{-} 3\right.$ nuclei per droplet). The nuclei were then punctured with a fine needle and the nucleoplasm allowed to disperse for $5-30 \mathrm{~min}$ at about $10{ }^{\circ} \mathrm{C}$. In some preparations the lampbrush chromosomes were freed from nucleolar material by removing the nuclear envelope together with the tightly adhering extrachromosomal nucleoli in the case of amphibian oocytes, or by spreading the supernatant after a short centrifugation step in the case of Acetabularia (Spring et al. 1975). The dispersed and swollen material in a drop was centrifuged either $(a)$ on to a carbon-coated electron-microscopic grid freshly charged by the glow discharge method, and stained with ethanolic phosphotungstic acid (PTA) as described by Miller \& Bakken (1972) (see also Scheer, Trendelenburg \& Franke, 1973) or (b) centrifuged on to a collodion-coated grid reinforced 
with carbon and positively charged by the glow discharge method in an atmosphere saturated with methylamine (Dubochet, Ducommun, Zolinger \& Kellenberger, 197I), and stained for $20 \mathrm{sec}$ in $0.1 \%$ uranyl formate (Brack \& Pirotta, 1975). In addition, some preparations were metal shadowed with platinum-paladium $(80: 20)$ at an angle of $7^{\circ}$. In some experiments chromatin was dispersed in solutions containing $0.1-0.5 \%$ of the anionic detergent Sarkosyl NL-30 (Ciba-Geigy, Basel, Switzerland) and $0^{\circ}$ I $\mathrm{mm}$ borate buffer, $\mathrm{pH} 9{ }^{\circ}$. After Io min the material was centrifuged as described above.

\section{RESULTS}

When lampbrush chromosomes from amphibian oocytes (Fig. I) and primary nuclei of Acetabularia (Fig. 3) are exposed for relatively short time spans to low salt concentrations, they show a rather compact appearance in the electron microscope. Chromomeres are not resolved as individual units, but appear to be fused into a very compact and electron-dense axial mass from which numerous lateral loops protrude (Fig. I). A very common form of loops (for example, those of the chromosome segment shown in Fig. I) are densely covered over the whole loop length with matrix material. Thin and thick ends of such loops can be distinguished at their insertion sites at the chromosome axis, but a gradual increase in the thickness of the matrix layer is usually only recognized in proximal parts of loops (Figs. I, 3). Most of the remaining loop axes are covered by a uniform, 0.5 to $\mathrm{I} \mu \mathrm{m}$ thick coat of matrix material. The lengths of such lateral loops as measured in electron-microscopic preparations vary greatly in amphibian oocyte chromosomes. They range from a few micrometres (Figs. I, 8) to about $55 \mu \mathrm{m}$ (Fig. I). They are somewhat more uniform (around $10 \mu \mathrm{m}$ ) in primary nuclei of Acetabularia (Figs. 3, 12). Loops larger than Iо० $\mu \mathrm{m}$ which are present in light-microscopic spread preparations of amphibian oocyte chromosomes (Fig. 2; see also the references quoted in the Introduction) are difficult to trace in electron micrographs, since they often tend to collapse. During the more extensive swelling of the chromosomes in ' $\mathrm{pH}$ 9-water' (see Methods) the matrix material undergoes a transition from the compact to a loosely packed state, thereby revealing the numerous individual lateral fibrils attached to the loop axis (Figs. 4-I4; cf. Miller \& Bakken, I972; Miller et al. 1972; Hamkalo \& Miller, I973; Spring et al. 1974, 1975). Some unravelling is also observed in the chromomeric regions. Depending on the specific spreading conditions, the chromomeres appear either very

Figs. I-3. Light (Fig. 2) and electron micrographs (Figs. I, 3) of segments of lampbrush chromosomes isolated from oocyte nuclei of Triturus cristatus (Fig. I), T. alpestris (Fig. 2) and primary nuclei of Acetabularia cliftonii (Fig. 3). Due to incomplete dispersion of the chromosomal material (incubation in $\mathrm{pH} 9$-medium was for only about I $\mathrm{min}$ ) the material associated with the lateral loops as well as the chromosomal axis appears very condensed. Note the numerous lateral loops of variable lengths, some with a clearly recognizable thin and thick terminal region at their insertion ends in the condensed chromomeric regions of the chromosome (e.g. at the arrows in Fig. I; this loop has a length of $55 \mu \mathrm{m}$ ). A gradual increase in the thickness of the matrix material coating the loop axis is especially evident in Fig. 3. The light micrograph shows an example of a large loop (total length $c a$. I $10 \mu \mathrm{m}$ ) which reveals a discontinuity in the thickness of the loop matrix material (Fig. 2, arrow). Fig. I, $\times 3000$; Fig. 2, $\times 950$; Fig. 3, $\times 17000$; bars represent 10,20 , and $\mathrm{I} \mu \mathrm{m}$ respectively. 


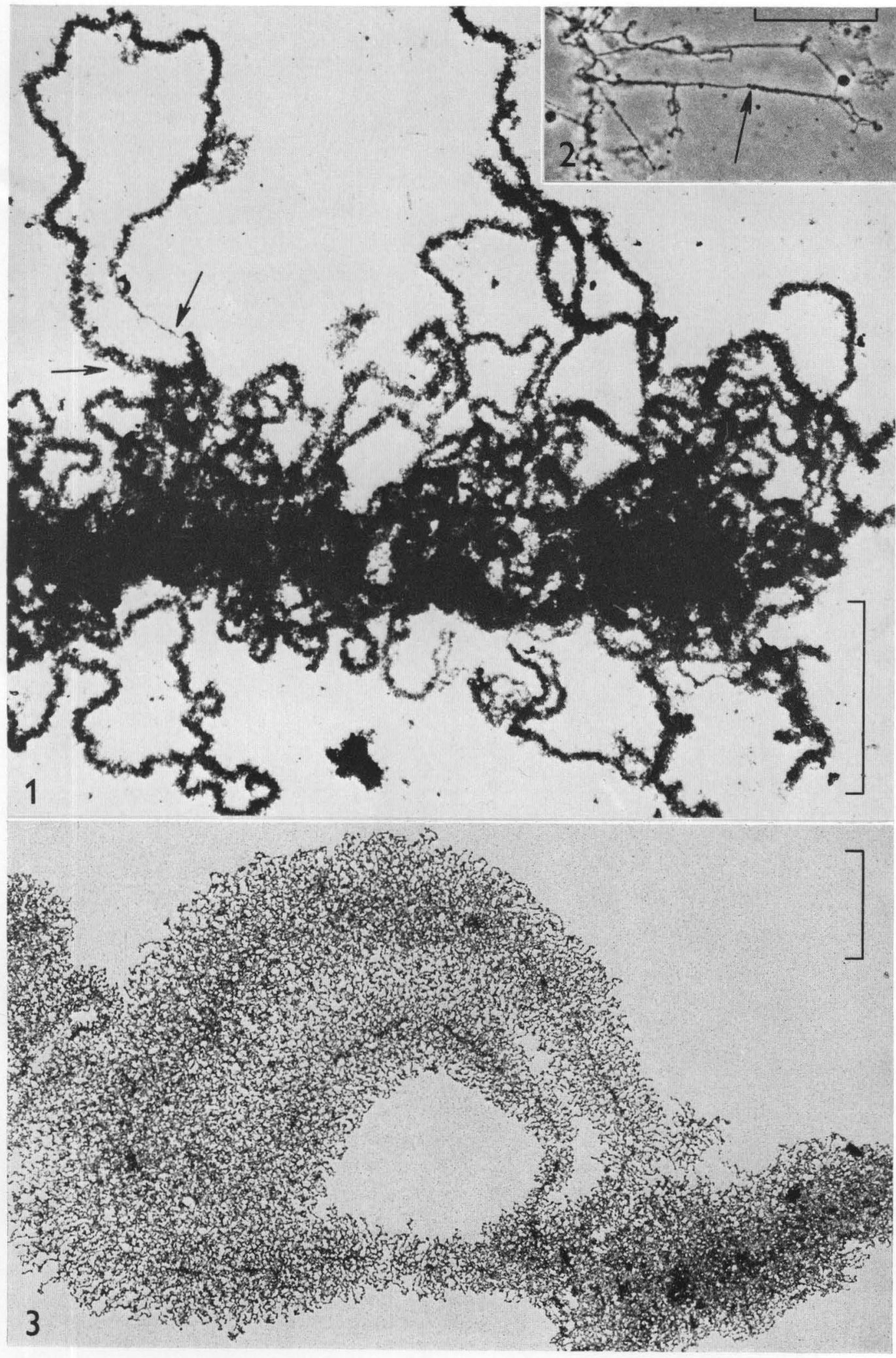




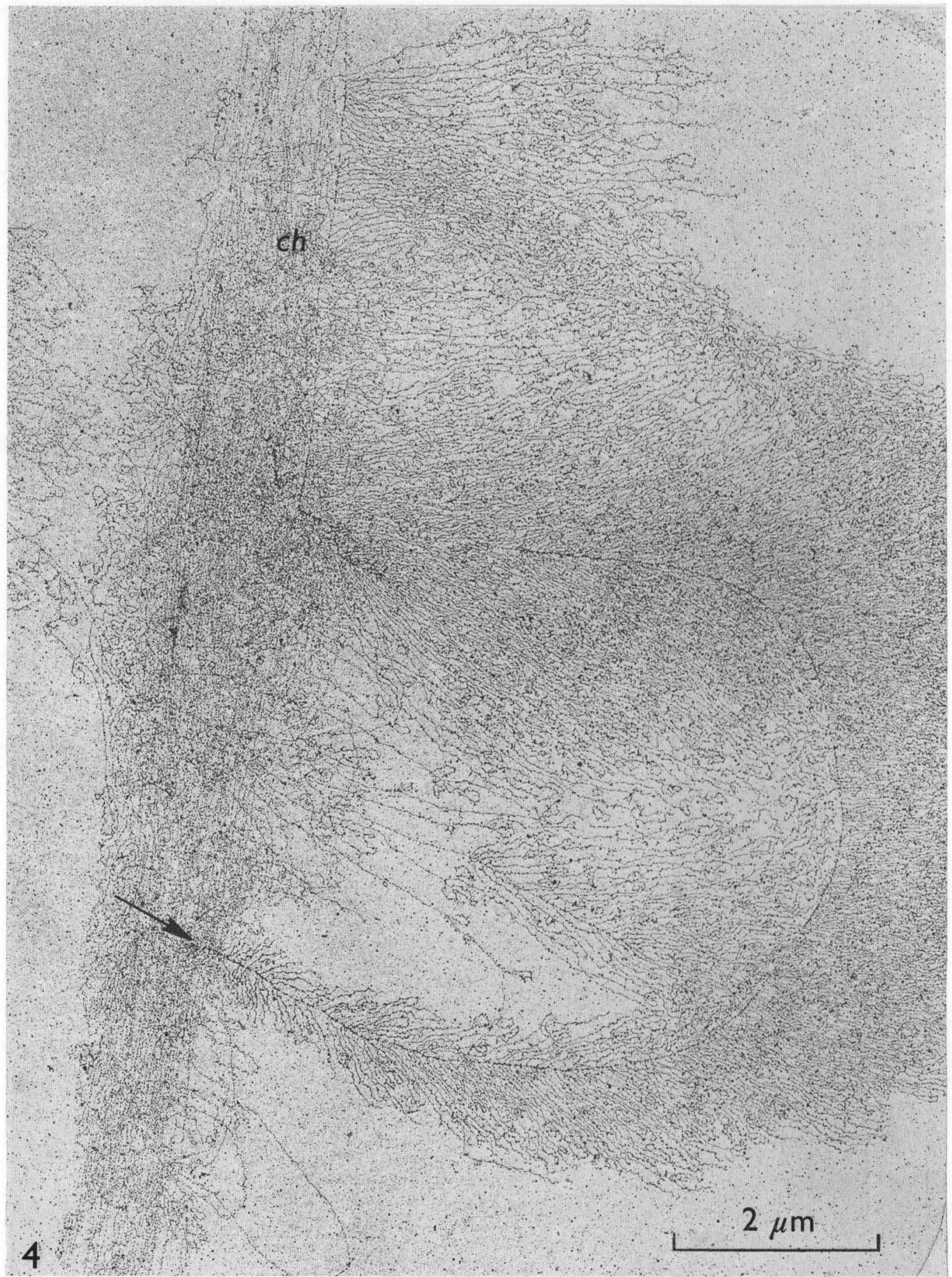

Fig. 4. Electron-microscopic appearance of a well spread loop and the associated chromomeric region $(\mathrm{ch})$ in a chromosome isolated from an oocyte of Pleurodeles waltli. The axis of the loop (about $15 \mu \mathrm{m}$ long) is clearly visible and is accentuated by the attachment of closely spaced basal granules of the numerous lateral fibrils. The lateral fibrils are arranged in a length gradient starting from the 'thin' insertion region (arrow). Note that several extended fibrils are to be seen in the chromosomal axis. $\times$ I 5500 . 


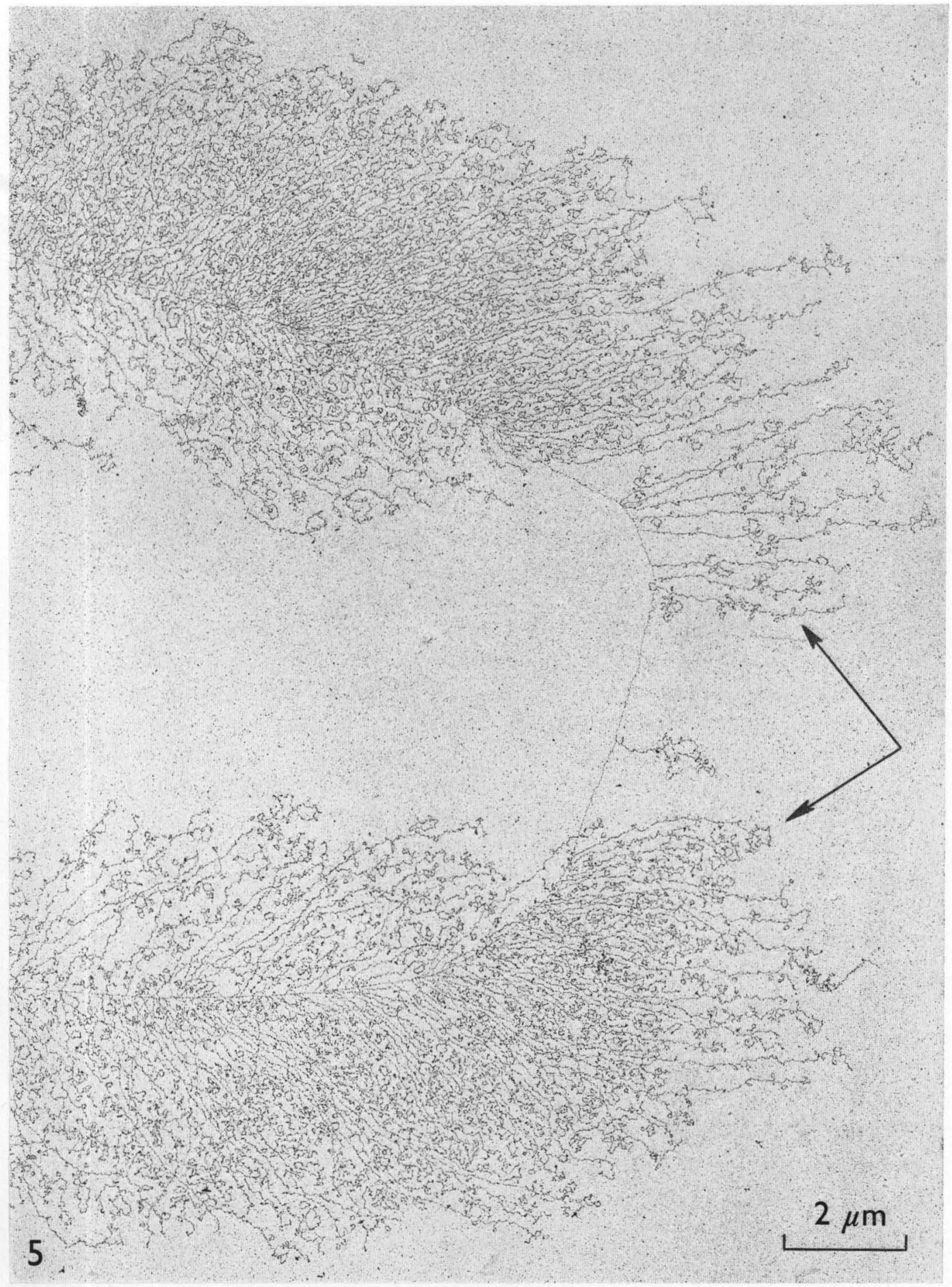

Fig. 5. Same preparation as in Fig. 4. The pair of arrows denote a gap within a matrix unit indicating a discontinuity in the transcriptional events (for details see text). Most of the nascent ribonucleoprotein (RNP) fibrils appear folded and/or coiled. $\times 9000$. 
compact (Fig. 8) or can be resolved to contain bundles of numerous, often parallel chromatin axes which are normally free of lateral fibrils (e.g. Fig. 4). The loop axis shown in Fig. 4 is covered by an uninterrupted series of densely packed lateral fibrils arranged in a length gradient that starts from its 'thin' chromomeric insertion site. According to the interpretation of Miller and coworkers (Miller \& Beatty, i969; Miller \& Bakken, 1972; Miller et al. 1972; Hamkalo \& Miller, 1973), each lateral ribonucleoprotein fibril together with its basal granule represents a transcriptional complex consisting of an RNA polymerase molecule (in the present study presumably of type B) and a nascent RNA chain complexed with specific proteins (Scott \& Sommerville, I974; Sommerville \& Malcolm, I976). In some loops, the axial chromatin strand appears to be totally transcribed. Examples are presented in Fig. 4 (loop length $\mathrm{I} 5 \mu \mathrm{m}$ ) and Fig. 8 (loop length 1o $\mu \mathrm{m}$ ). Here one loop obviously represents one transcriptional unit. The lateral fibrils largely appear to be extended (Fig. 4) but are usually shorter than the specific axial intercept from the beginning of the unit to the fibril base. This suggests that either the nascent RNA is coiled up within the RNP fibril or that 'processing' cleavage of the growing RNA occurs similar to the situation described in nucleolar transcriptional units (for detailed discussion see Franke et al. I976). Especially when the lateral fibrils have reached a length of about $2 \mu \mathrm{m}$, they reveal a tendency not only to tangle with each other but also to coil up at certain sites and form small ring-like or complex bush-like structures (Figs. 5, 9, Io; cf. also Miller et al. I972; Angelier \& Lacroix, I975; Glätzer, I975). Occasionally, such small ring structures with diameters of about $0.05^{-0.1} \mu \mathrm{m}$ are aligned along a lateral RNP fibril without any visible connexion to it (e.g. Fig. I4). In transcriptional units, or in parts thereof, with maximal fibril density, the distances between the bases of the lateral fibrils (i.e. the distances between adjacent RNA polymerase complexes on the loop axis) are comparable to those determined for fully active genes coding for the ribosomal RNA precursor (e.g. Miller \& Beatty, I969; Scheer et al. 1973, I976a; Trendelenburg, Scheer \& Franke, 1973; Trendelenburg, 1974; Spring et al. 1974; Meyer $\&$ Hennig, $1974 b$ ). This closeness of the lateral fibrils indicates a very high transcriptional activity of the lampbrush chromosome loops (e.g. Figs. $4^{-1} 3$ ). In some preparations, 'gaps' (fibril-free axial regions of variable length) are present within otherwise normal matrix units (Fig. 5). We do not know whether this is due to the artificial removal of some lateral fibrils during preparation or whether perhaps it reflects true discontinuities in transcriptional events (cf. Scheer et al. r976a, b). The exertion of some mechanical stress during preparation is indicated by the occasional occurrence of asymmetrical distributions of the lateral fibrils on either side of the loop axis (Figs. 5, I4; for detailed discussion on methodological problems see also

Figs. 6, 7. Lampbrush chromosome loop (total length $53 \mu \mathrm{m}$ ) of an oocyte from Triturus cristatus showing one functional transcriptional unit. This loop contains a transcribed portion (arrows in Fig. 6) limited by a preceding and a subsequent fibril-free, i.e. apparently non-transcribed, intercept (25 and $13 \mu \mathrm{m}$ in length). The transcriptional unit is shown at higher magnification in Fig. 7, where the start region is indicated by an arrow. Fig. $6, \times 7500$; Fig. $7, \times 17000$; bars represent 2 and $\mathrm{I} \mu \mathrm{m}$, respectively. 


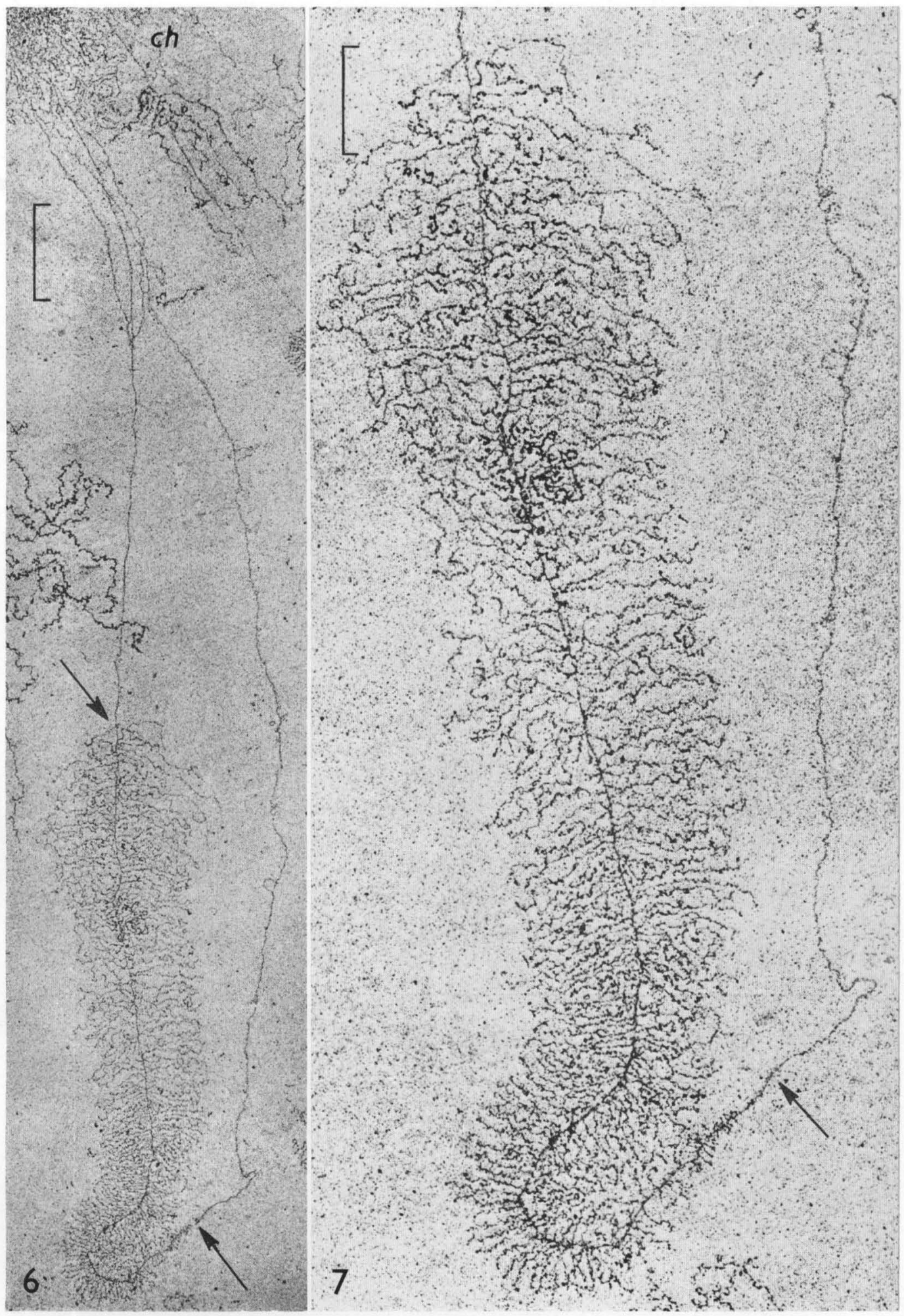


Scheer et al. I973). The larger spacings of lateral fibrils on the axes of some loops (Fig. I4; see also the spread preparations of lampbrush chromosomes of Drosophila hydei spermatocytes by Meyer \& Hennig, I974a; Hennig et al. 1974; Glatzer, 1975) are reminiscent of the situation described for ribosomal RNA precursor genes of reduced transcriptional activity (Scheer et al. 1976a, $b$ ).

Several arrangements of matrix units can be distinguished in spread and positively stained loops that are in principle different from each other (compare the schemes in Fig. I 5). (a) Loops which contain only one matrix unit that extends for the entire loop length (see Figs. I, 3, 4) and correspond to the 'classic' view of the organization of the chromosome loops derived from light microscopy (for references see Introduction) and from electron micrographs of thin sections (Mott \& Callan, 1975) and spread preparations (Meyer \& Hennig, r974a ; Miller, I965). (b) Apparently untranscribed regions recognized in a considerable number of loops which contain only one matrix unit; such regions may be located before and/or subsequent to a complete matrix unit (e.g. Figs. 6, 7). (c) Loops with two or more matrix units of different lengths arranged with identical polarity; such loops are frequent in the primary nuclei of dasycladacean green algae (cf. Spring et al. 1975) but seem to be less commonly found in lampbrush chromosomes of amphibian oocytes and insect spermatocytes (cf. Angelier \& Lacroix, I975; Hennig et al. I974). (d) Loops with several matrix units of the same or similar lengths have not yet been unequivocally demonstrated; however, our observations do not exclude such a mode of arrangement. (e) Loops with two or more transcriptional units of similar or different lengths that reveal alterations in the polarity of the transcription; interestingly, these are rather frequently observed in both cell systems examined (Figs. 9, I I-I3; cf. Spring et al. I974; Angelier \& Lacroix, I975). This may indicate either transcription from different DNA strands in different regions of the loop, or, in our opinion less likely, inversion of polarity within one loop (as to the occurrence of such switches in polarity, see Wolff, Lindsley \& Peacock, I976). ( $f$ ) Interspersed, more or less extended, apparent spacer regions in the multigenic loops; these are found in a large proportion of loops (Figs. I I-I3; c.f. Spring et al. 1974; Hennig et al. 1974; Angelier \& Lacroix, 1975). Loops with arrangements of transcriptional units other than the classic type (A in Fig. I5) may explain discontinuities in the thickness of the matrix material occasionally observed in loops with the electron microscope at low magnification

Figs. 8-ro. Details of the electron-microscopic appearance of chromosome loops in oocytes from Triturus cristatus (Fig. 8) and Pleurodeles walti (Figs. 9, 10). The chromomere-loop complex shown in Fig. 8 has been prepared according to the 'Dubochet' technique (see Methods). The thin insertion point of the upper loop (total length $c a$. го $\mu \mathrm{m}$ ) at the highly condensed chromomeric region $(c h)$ is indicated by the single arrow. The initial and terminal RNP fibrils of the matrix unit appear to be separated from the chromomeric region by short, apparently untranscribed intercepts of the loop axis. Note the small loop in the bottom part of Fig. 8 (pair of arrows, total length $c a .3 .5 \mu \mathrm{m}$ ). Fig. 9 presents an example of opposite polarity (double headed arrow) of 2 adjacent transcriptional units. The complex structure of the lateral RNP fibrils attached to more terminal regions of such a transcriptional unit is shown in Fig. 10. Fig. 8, × 22000 ; Figs. 9, 10, $\times 9000$. 

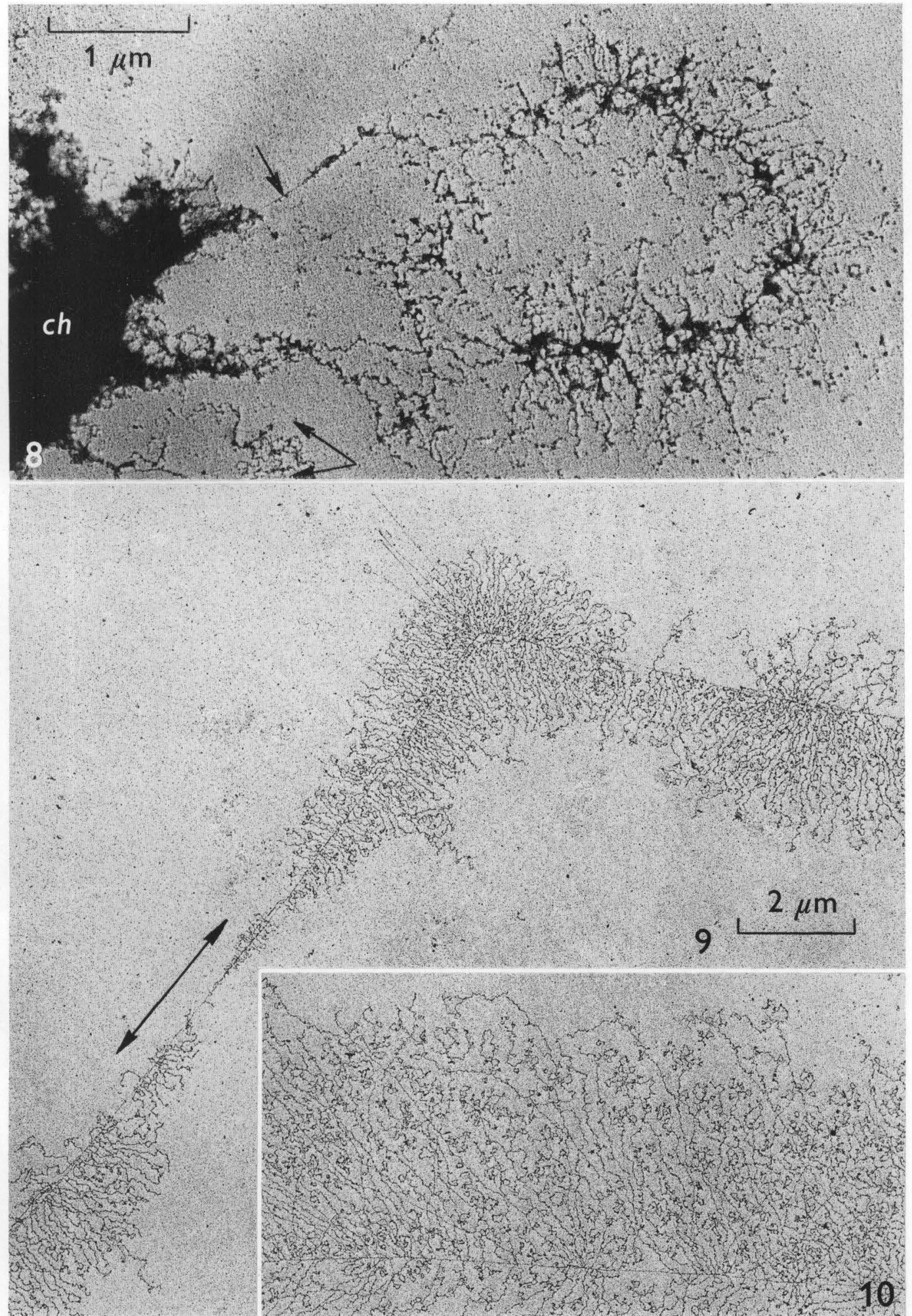


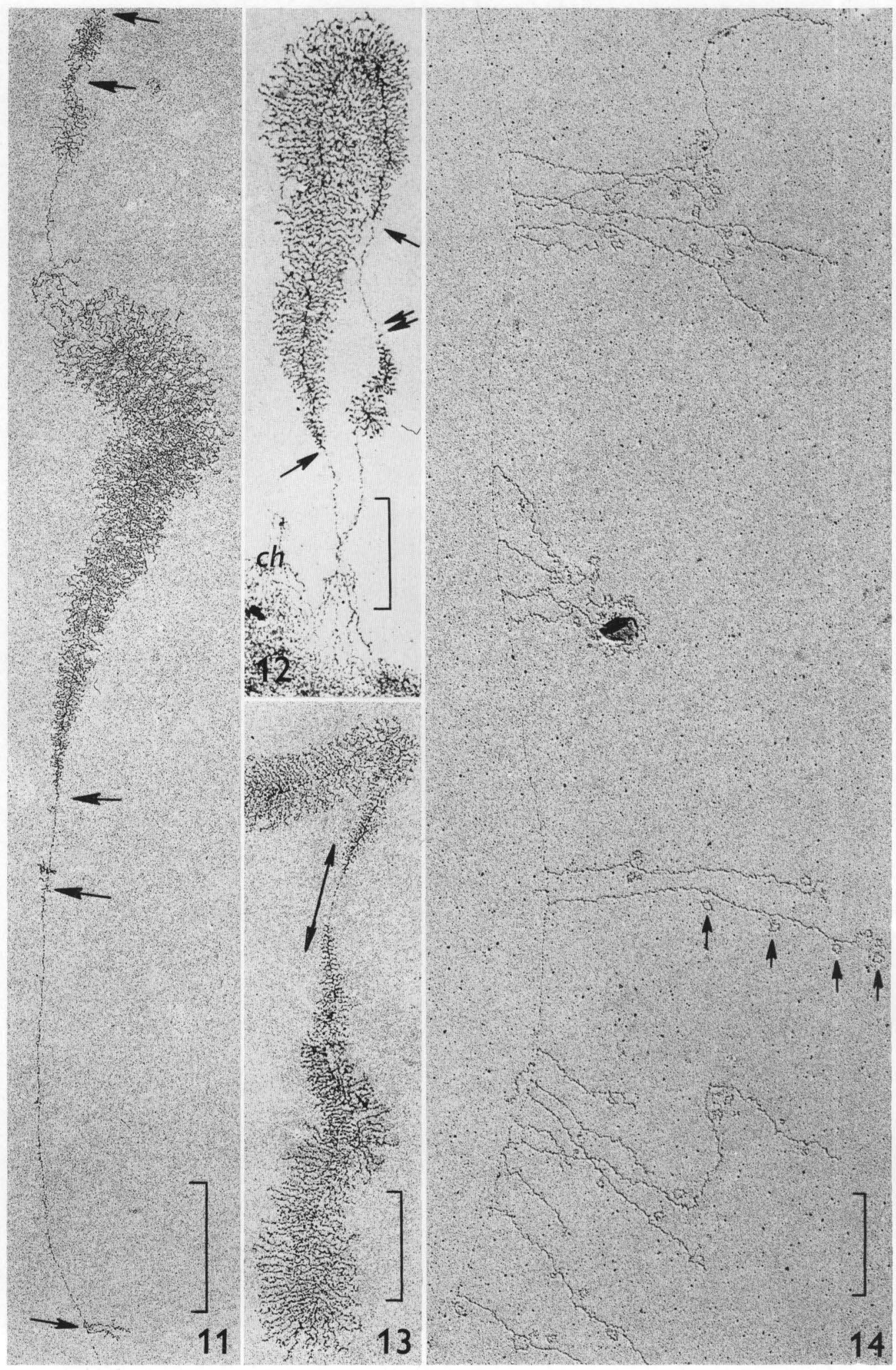




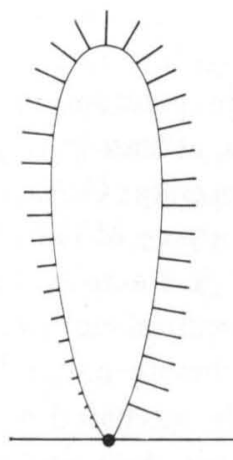

A

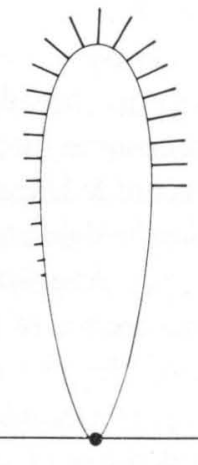

B

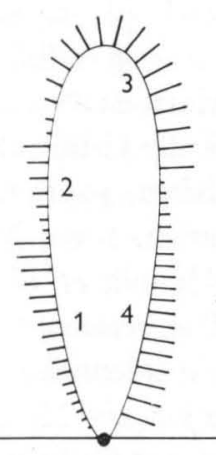

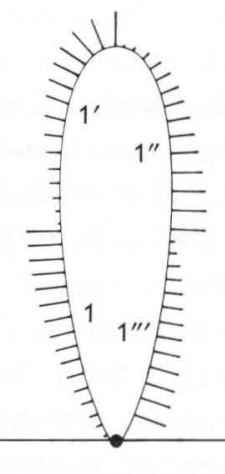

D

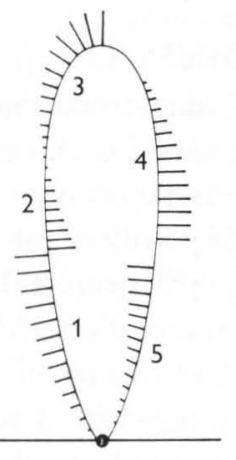

E

Fig. I 5. Various alternatives for arrangements of transcriptional units within individual loops of lampbrush chromosomes. The numbers $\mathrm{I}^{-\mathrm{I}^{\prime \prime \prime}}$ denote units of equal, $\mathrm{I}-5$ of different lengths. For further details see text.

(cf. fig. $4 b$ in Ullerich, I970) or with the light microscope in lampbrush chromosomes of amphibian oocytes (e.g. Fig. 2; the 'interruptions' sensu Callan, I963; Mott \& Callan, 1975; Callan, personal communication). Information is insufficient to determine whether such configurations seen in the light microscope can be correlated exactly with a particular electron-microscopic equivalent as diagrammed in Fig. I5, but the arrangements illustrated do account for certain light-microscopic features such as the discontinuities noted above.

Figs. II-I3. Examples of different arrangements of two or more transcriptional units along individual loops of lampbrush chromosomes isolated from primary nuclei of Acetabularia major (Fig. II), A. mediterranea (Fig. I2) and A. cliftonii (Fig. I3). The 2 upper arrows in Fig. I I denote start regions of closely spaced, relatively short matrix units with identical polarity whereas the large matrix unit (total length $c a .8 \mu \mathrm{m}$; the origin is indicated by the arrow in the middle part of Fig. I I) contains a unit that is transcribed in the opposite direction. Note also, in Fig. I I, the occasional occurrence of small isolated groups of lateral fibrils in extended, otherwise fibril-free regions (e.g. at the 2 lower arrows). The loop shown in Fig. I 2 (total length $c a$. I I $\mu \mathrm{m}$ ) contains 2 matrix units in an end-to-end arrangement (their start regions denoted by arrows) and a small matrix unit (double arrow), separated by an apparently non-transcribed axial intercept. The fibril-covered, i.e. transcribed, portions of this specific loop are separated from the chromomeric region $(c h)$ by intercepts of about $\mathbf{I} \mu \mathrm{m}$. Two matrix units arranged start-to-start (double headed arrow) are shown in Fig. I3. Fig. II, $\times$ I0000; Figs. I2, I3, $\times$ I7000; bars represent 2 and I $\mu \mathrm{m}$, respectively.

Fig. I4. Part of a lampbrush loop from an oocyte of Triturus cristatus with a much reduced density of lateral fibrils indicative of greatly lowered transcriptional activity. The chromosomes were dispersed in medium containing $0.1 \%$ Sarkosyl NL-30 which results in the removal of most of the chromosomal proteins but leaves the transcriptional complexes attached to the thin $(c a .5 \mathrm{~nm})$ loop axis. Note the occurrence of small, ring-like structures associated with the lateral RNP fibrils (some are denoted by arrows). The preparation has been both positively stained and metal shadowed. $\times$ I6 000 ; bar represents I $\mu \mathrm{m}$. 


\section{DISCUSSION}

Loop structures observed in the electron microscope in spread preparations can be correlated with the light-microscopically visible chromosome loops, at least in respect of the larger ones (e.g. Tomlin \& Callan, I95 I ; Guyénot \& Danon, I953; Gall, I956, I966; Miller, I965; Ris, I969; Ullerich, I970; Miller \& Bakken, I972; Miller et al. 1972; Meyer \& Hennig, 1974a; Hennig et al. 1974; Angelier \& Lacroix, 1975; Sommerville \& Malcolm, I976). The occasional occurrence of artificial unravelling and extension of strands from the condensed part of the chromomere into a loop structure (for a schematic presentation see Hess, I97I) cannot be excluded at the moment. Nevertheless, we interpret our findings and those of others (see above) as reflecting the true mode of arrangement of transcriptional units within the generality of the loops described, for light- and electron-microscopic measurements of loop lengths are in fair correspondence.

Several of the various modes of arrangement of transcriptional units that can be hypothetically designed (for example, the situations diagrammed in Figs. ${ }_{5} \mathrm{~A}-\mathrm{E}$ ) are electron-microscopically observed in well extended loop preparations: our studies (see also Spring et al. I974, I975) present illustrations with examples for the situations designated A, B, C and E in Fig. I5. Some loops (Fig. I $5 \mathrm{~A}$ ) represent the electronmicroscopic confirmation of the classic scheme derived from light-microscopic observations of the 'asymmetric' loop continuously covered with 'many fine fibres projecting radially from the axis' (Callan, I963). This structure has usually been interpreted in the sense that one loop is one transcriptional unit (Sommerville \& Malcolm, 1976). Other loops show one transcriptional unit but additional fibril-free regions that precede and/or follow the specific matrix unit (Fig. I 5 B). Such fibril-free intercepts of the loop axis could represent either gene-containing units not being transcribed or true 'spacers' for transcription, i.e. potentially untranscribable sequences, alternatives which at present cannot be decided between. The existence of such apparently untranscribed regions in loops demonstrates that loop size, whether determined by light or electron microscopy, is not necessarily correlated with the lengths, and cannot be used a priori in calculations of the lengths, of transcriptional units. Other types of loop ( $\mathrm{C}-\mathrm{E}$ in Fig. I 5) contain more than one matrix unit, i.e. more than one transcriptional unit, which illustrates the existence of truly multigenic loops. Some of the matrix units in such complex loops are rather short, indicating the occurrence of some premRNA molecules of molecular weights below $10^{6}$ Daltons among other transcripts from pre-mRNA genes which are much longer (cf. Sommerville \& Malcolm, i 976). Although we cannot exclude that some of these transcriptional units in multigenic loops represent non-translated sequences derived from 'ancient' genes (Sommerville \& Malcolm, I976) we prefer the view that the different transcriptional units found in such loops reflect the formation of different Hn-RNAs, probably also of different pre-mRNAs (for contrasting views see Beerman, I972). If this view is correct, it would also mean that such different genes are transcribed simultaneously and, consequently, that some loops contain a set of genes which constitutes a unit of transcriptionally coordinated genes which may also be functionally related (for detailed 
discussion see the recent review article by Lima-de-Faria, 1975). A considerable number of multigenic loops reveal differences in the polarity of their transcriptional units (as sketched in $\mathrm{E}$ of Fig. I 5). This indicates either intra-axial switches in DNApolarity (Wolff et al. 1976) or transcription from both strands, using the one strand in one region and the other in an adjacent region. Alternative transcription of the one or the other strand in adjacent intercepts of genomes are quite common in prokaryotic systems, including bacteriophages (e.g. Szybalski et al. 1970; Guha, Saturen \& Szybalski, I97r) and have also been described in the transcription of some animal viruses (e.g. Khoury et al. 1973; Kamen, Lindstrom, Shure \& Old, I974; Sharp, Gallimore \& Flint, 1974). This arrangement of transcriptional units in some loops further indicates that continuous travel of the RNA polymerase complexes into subsequent genes is excluded, and that detachment of the RNA polymerases from the termination site must occur.

We thank Professor H. G. Callan (University of St Andrews, Scotland) for valuable discussions and Dr D. J. Morré (Purdue University, Lafayette, USA) for reading and correcting the manuscript. The work has been supported by the Deutsche Forschungsgemeinschaft (grant Sche $157 / 2)$.

\section{REFERENCES}

Angelier, N. \& Lacroix, J. C. (I975). Complexes de transcription d'origines nucléolaire et chromosomique d'ovocytes de Pleurodeles waltiii et P. poireti (Amphibiens, Urodèles). Chromosoma 51, 323-335.

Barsacchi-Pilone, G., Nardi, I., Batistoni, R., Andronico, F. \& Beccari, E. (i974). Chromosome location of the genes for $28 \mathrm{~S}$, $\mathrm{I} 8 \mathrm{~S}$ and ${ }_{5} \mathrm{~S}$ ribosomal RNA in Triturus marmoratus (Amphibia, Urodela). Chromosoma 49, I35-153.

BeErmann, W. (1972). Chromomeres and genes. In Developmental Studies on Giant Chromosomes (ed. W. BeERManN), pp. I-33. Berlin: Springer.

Brack, C. \& Pirotta, V. (r975). Electron microscopic study of the repressor of bacteriophage $\lambda$ and its interaction with operator DNA. F. molec. Biol. 96, I39-1 52.

Callan, H. G. (1963). The nature of lampbrush chromosomes. Int. Rev. Cytol. r5, r-34.

Callan, H. G. \& Lloyd, L. (1960a). Lampbrush chromosomes. In New Approaches in Cell Biology (ed. P. M. B. Walker), pp. 23-46. London: Academic Press.

Callan, H. G. \& Lloyd, L. (I960b). Lampbrush chromosomes of crested newts Triturus cristatus (Laurenti). Proc. R. Soc. B 243, I35-2 12.

Dubochet, J., Ducommun, M., Zollinger, M. \& Kellenberger, E. (i971). A new preparation method for dark-field electron microscopy of biomacromolecules. $\mathscr{J}$. Ultrastruct. Res. 35, I $47-167$.

Franke, W. W., Scheer, U., Spring, H., Trendelenburg, M. F. \& Krohne, G. (i976). Morphology of transcriptional units of rDNA: evidence for transcription in apparent spacer intercepts and cleavages in the elongating nascent RNA. Expl Cell Res. 1oo, 233-244.

GaLL, J. G. (1954). Lampbrush chromosomes from oocyte nuclei of the newt. F. Morph. 94, 283-35I.

Gall, J. G. (1956). On the submicroscopic structure of chromosomes. Brookhaven Symp. Biol. 8, I7-32.

Gall, J. G. (I966). Techniques for the study of lampbrush chromosomes. In Methods of Cell Physiology, vol. 2 (ed. D. M. Prescott), pp. 37-60. New York: Academic Press.

Gall, J. G. \& Callan, H. G. (1962). $\mathrm{H}^{3}$-uridine incorporation in lampbrush chromosomes. Proc. natn. Acad. Sci. U.S.A. 48, 562-570.

GLÄTZER, K. H. (1975). Visualization of gene transcription in spermatocytes of Drosophila hydei. Chromosoma 53, 371-379. 
Georgiev, G. P. (I974). Precursor of mRNA (pre-mRNA) and ribonucleoprotein particles containing pre-mRNA. In The Cell Nucleus, vol. 3 (ed. H. Busch), pp. 67-ro8. New York: Academic Press.

Guha, A., Saturen, Y. \& Szybalski, W. (I97I). Divergent orientation of transcription from the biotin locus of Escherichia coli. F. molec. Biol. 56, 53-62.

Guyenot, E. \& Danon, M. (1953). Chromosomes et ovocytes de batraciens. Etude cytologique et au microscope électronique. Revue suisse Zool. 6o, I-I29.

Hamkalo, B. A. \& Miller, O. L. (1973). Electronmicroscopy of genetic activity. A. Rev. Biochem. 42, 379-396.

Hennig, W., Meyer, G. F., Hennig, I. \& Leoncini, O. (1974). Structure and function of the Y chromosome of Drosophila hydei. Cold Spring Harb. Symp. quant. Biol. 38, 673-683.

Hess, O. (I97 I). Lampenbürstenchromosomen. In Handbuch der allgemeinen Pathologie, vol. 2 part 2 (ed. H. W. Altmann), pp. 215-281. Berlin: Springer.

Hill, R. J., Maundrell, K. \& Callan, H. G. (i974). Non-histone proteins of the oocyte nucleus of the newt. F. Cell Sci. 15, I45-I6r.

Izawa, M., Allfrey, V. G. \& Mirsky, A. E. (I963). The relationship between RNA synthesis and loop structure in lampbrush chromosomes. Proc. natn. Acad. Sci. U.S.A. 49, 544-55 I.

Kamen, R., Lindstrom, D. M., Shure, H. \& Old, R. W. (1975). Virus-specific RNA in cells productively infected or transformed by polyoma virus. Cold Spring Harb. Symp. quant. Biol. 39, 187-198.

Khoury, G., Martin, M. A., Lee, T. N. H., Danna, K. J. \& Nathans, D. (I973). A map of simian virus 40 transcription sites expressed in productively infected cells. F. molec Biol. $\mathbf{7 8}$, $377-389$.

KunZ, W. (I967). Lampenbürstenchromosomen und multiple Nukleolen bei Orthopteren. Chromosoma 21, 446-462.

LiMA-DE-FARIA, A. (1975). The relation between chromomeres, replicons, operons, transcription units, genes, viruses and palindromes. Hereditas $\mathbf{8 1}, \mathbf{2 4 9 - \mathbf { 2 } 8 4}$.

MacgReGOR, H. C. \& Callan, H. G. (I962). The actions of enzymes on lampbrush chromosomes. Q. Fl microsc. Sci. 103, 173-203.

Malcolm, D. B. \& Sommerville, J. (1974). The structure of chromosome-derived ribonucleoprotein in oocytes of Triturus cristatus carnifex (Laurenti). Chromosoma 48, I37-I58.

Maundrell, K. (1975). Proteins of the newt oocyte nucleus: analysis of the non-histone proteins from lampbrush chromosomes, nucleoli and nuclear sap. F. Cell Sci. 17, 579-588.

Meyer, G. F. \& Hennig, W. (r974a). Molecular aspects of the fertility factors in Drosophila. In The Functional Anatomy of the Spermatozoon (ed. B. A. Afzelius), pp. 69-75. Oxford: Pergamon.

Meyer, G. F. \& Hennig, W. (1974b). The nucleolus in primary spermatocytes of Drosophila hydei. Chromosoma 46, $12 \mathrm{I}-\mathrm{I} 44$.

Miller, O. L. (1965). Fine structure of lampbrush chromosomes. Natn. Canc. Inst. Monogr. I8, 79-99.

Miller, O. L. \& Bakken, A. H. (1972). Morphological studies of transcription. Acta endocr., Suppl. 168, I 55-177.

Miller, O. L. \& Beatty, B. R. (i 969). Visualization of nucleolar genes. Science, N. Y. r64, 955-957.

Miller, O. L., Beatty, B. R. \& Hamkalo, B. A. (1972). Nuclear structure and function during amphibian oogenesis. In Oogenesis (ed. J. D. Biggers \& A. W. Schuetz), pp. I 19-I 28. Baltimore: University Park Press.

Мотт, M. R. \& Callan, H. G. (1975). An electron-microscope study of the lampbrush chromosomes of the newt Triturus cristatus. F. Cell Sci. 17, 241-26r.

Paul, J. (1975). The transcriptional unit in eukaryotes. Genetics, Princeton 79, I5 I-I 57.

Pukkila, P. J. (I975). Identification of the lampbrush chromosome loops which transcribe ${ }_{5} \mathrm{~S}$ ribosomal RNA in Notophthalmus (Triturus) viridescens. Chromosoma 53, 71-89.

Ris, H. (1969). The molecular organization of chromosomes. In Handbook of Molecular Cytology (ed. A. Lima-de-Faria), pp. 222-25o. Amsterdam: North-Holland Publishing.

Rosbash, M., Ford, P. J. \& Bishop, J. O. (i 974$)$. Analysis of the $C$-value paradox by molecular hybridization. Proc. natn. Acad. Sci. U.S.A. 71, 3746-3750.

Scheer, U., Trendelenburg, M. F. \& Franke, W. W. (1973). Transcription of ribosomal RNA cistrons. Correlation of morphological and biochemical data. Expl Cell Res. 8o, 175-190. 
Scheer, U., Trendelenburg, M. F. \& Franke, W. W. (I976a). Regulation of transcription of genes of ribosomal RNA during amphibian oogenesis. F. Cell Biol. 69, 465-489.

Scheer, U., Trendelenburg, M. F. \& Franke, W. W. (I976 $b$ ). Regulation of transcription of ribosomal RNA-genes during amphibian oogenesis. In Progress in Differentiation Research (ed. N. Müller-Bérat), pp. 105-118. Amsterdam: North-Holland Publishing.

Scott, S. E. M. \& Sommerville, J. (1974). Location of nuclear proteins on the chromosomes of newt oocytes. Nature, Lond. 250, 680-682.

Sharp, P. A., Gallimore, P. H. \& Flint, S. J. (I975). Mapping of adenovirus 2 RNA sequences in lytically infected cells and transformed cell lines. Cold Spring Harb. Symp. quant. Biol. 39, 457-474.

Snow, M. H. L. \& Callan, H. G. (1969). Evidence for a polarized movement of the lateral loops of newt lampbrush chromosomes during oogenesis. F. Cell Sci. 5, I-25.

Sommerville, J. (I 973). Ribonucleoprotein particles derived from the lampbrush chromosomes of newt oocytes. F. molec. Biol. 78, 487-503.

Sommerville, J. \& Malcolm, D. B. (1976). Transcription of genetic information in amphibian oocytes. Chromosoma 55, $183-208$.

Spring, H., Trendelenburg, M. F., Scheer, U., Franke, W. W. \& Herth, W. (1974). Structural and biochemical studies of the primary nucleus of two green algal species, Acetabularia mediterranea and Acetabularia major. Cytobiologie ro, I-65.

Spring, H., Scheer, U., Franke, W. W. \& Trendelenburg, M. F. (1975). Lampbrush-type chromosomes in the primary nucleus of the green alga Acetabularia mediterranea. Chromosoma 50, 25-43.

Szybalski, W., Bøvre, K., Fiandt, M., Hayes, S., Hradecna, Z., Kumar, S., Lozeron, H. A., Nijkamp, H. J. J. \& Stevens, W. F. (1970). Transcriptional units and their controls in Escherichia coli Phage: Operons and Scriptons. Cold Spring Harb. Symp. quant. Biol. 35, $341-353$.

Tomlin, S. G. \& Callan, H. G. (1951). Preliminary account of an electron microscope study of chromosomes from newt oocytes. Q. Fl microsc. Sci. 92, 221-224.

TrendelenburG, M. F. (1974). Morphology of ribosomal RNA cistrons in oocytes of the water beetle Dytiscus marginalis L. Chromosoma 48, I19-135.

Trendelenburg, M. F., Scheer, U. \& Franke, W. W. (I973). Structural organization of the transcription of ribosomal DNA in oocytes of the house cricket. Nature, New Biol. 245, I67-170.

Ullerich, F. H. (1970). DNS-Gehalt und Chromosomenstruktur bei Amphibien. Chromosoma 3o, I-37.

Wischnitzer, S. (1957). A study of the lateral loop chromosomes of amphibian oocytes by phase contrast microscopy. Am. F. Anat. 1or, 135-167.

Wolff, S., Lindsley, D. L. \& Peacock, W. J. (1976). Cytological evidence for switches in polarity of chromosomal DNA. Proc. natn. Acad. Sci. U.S.A. 73, 877-88r.

(Received 29 June 1976) 